\title{
THE ART AND TECHNIQUE OF INTERPRETATION RECONSIDERED: THE COGNITIVE UNCONSCIOUS AND THE EMBODIED MIND VICTORIA STEVENS, Ph.D.
}

\author{
Psychologist-Psychoanalyst - Division 39 of the APA - Spring, 2005
}

\begin{abstract}
"We must endure our thoughts all night, until the bright obvious stands motionless in cold."

Wallace Stevens, (1954). "Man Carrying a Thing"
\end{abstract}

\section{INTRODUCTION}

The rapidly developing fields of interpersonal neurobiology with its grounding in attachment theory, affect regulation theory, developmental psychology and psychodynamic theory is creating a need to expand the understanding and operational definitions of certain commonly used therapeutic terms. At the same time, findings from other disciplines engaged in the study of the mind are also rethinking and redefining certain commonly held theoretical assumptions. These disciplines include cognitive science, philosophy, and linguistic theory - all of which are concerned with questions regarding the nature of the self, subjectivity, the mind and the brain. There are many points of intersection that are emerging from this interdisciplinary matrix of interpersonal developmental neurobiology, cognitive science, linguistic theory and 
psychodynamic therapeutic theory and technique. In this paper I am going to focus on one area of intersection - that of interpretation.

In their 1999 work Philosophy In the Flesh, cognitive scientists George Lakoff, a professor of linguistics and Mark Johnson, a professor of philosophy, state that there are three major findings from cognitive science that call for a questioning of the traditionally accepted understanding of reason within the Western philosophical tradition. These three findings are: "The mind is inherently embodied; thought is mostly unconscious; and abstract concepts are largely metaphorical" (p.3). The fundamental assumptions that these findings call into question are: we can know our own mind through introspection; most of our thinking about the world is literal; and that reason is disembodied and literal.

Lakoff and Johnson posit the term "cognitive unconscious" describes thinking that operates beneath the level of cognitive awareness, and is therefore inaccessible to consciousness because it occurs too quickly to be focused upon. In this formulation they expand the term "cognitive" to include "aspects of our sensorimotor system that contribute to our abilities to conceptualize and reason" (p.12). They further state, "Since cognitive operations are mostly unconscious, the term cognitive unconscious accurately describes all unconscious mental operations concerned with conceptual systems, meaning, inference and language" (p.12). Finally, they claim that "This shift in the understanding of reason is of vast proportions, and it entails a corresponding shift in our understanding of who we are as human beings" (p.5). 
While these findings (especially the first and second) have been understood by psychoanalytic theorists and clinicians for at least a century, this recent updating of the concept of unconscious operations by cognitive science is particularly relevant to current reformulations of psychodynamic theory. Given this reconceptualization of thought and reason, the question that arises regarding interpretation is: how can one embodied, largely unconscious and subjectively unique metaphoric mind understand the experience of another human being whose mind is also embodied, largely unconscious and equally subjectively unique in its own system of metaphors?

\section{LITERAL- SEMANTIC VS. CRITICAL-SEMIOTIC INTERPRETATIONS}

The philosopher Ricoeur (1974) defines interpretation as "the work of thought which consists of deciphering the hidden meaning in the apparent meaning, in unfolding the levels of meaning implied in the literal meaning" (p.13). He goes on to say that although "interpretation begins with multiple determinations of symbols...each interpretation, by definition, reduces this richness, this multivocity, and 'translates' the symbol according to its own frame of reference" (p.14). Within Ricoeur's definition lie the two basic kinds of interpretation as understood by linguistic theory: the semantic or literal interpretation of a text or communication, and the critical or semiotic approach.

The first, literal interpretation is a form of decoding or translating the literal meaning of words or actions based upon some assumed theoretical understanding that is acting as a selective lens of perception. On the other hand, the second, critical interpretation assumes the ability on the part of the 
interpreter to remain open to the entire and ever-changing context of whatever is being interpreted, and while still being subjective, to attempt to understand the particular intent and language/mind of the person making the communication. This is an area where interpersonal neurobiology contributes in an important way, by exploring in detail how the self-regulating and essentially right-brained empathic attunement of the analyst facilitates the critical type of interpretation (Schore 2003).

In psychoanalysis, a "good" interpretation is considered to be one of the most important factors in the therapeutic growth and development of the patient. The many functions of interpretations include the expansion of the patient's ability to tolerate feelings - including anxiety and the pain of love and loss; the capacity to recognize and think about these feelings; the awareness of what has previously been unconscious; and the ability to think, be and play creatively.

Ogden (2001) brings this discussion of interpretation closer to the current findings in cognitive science and interpersonal neurobiology when he says that psychoanalysis is moving in terms of its hermeneutics from attempting to deduce and discover "the meaning" of a symptom, word, sentence, association, dream narrative or pattern of behaviors, to an understanding of meaning only in terms of the larger context which is always intersubjective. He states that the question "What does that mean?" is expanding to include such questions as "What is going on here?" In terms of analytic technique, he calls for a new kind of language of interpretation - one 
that is informed heavily by an understanding of the particular metaphoric use of language by a patient and accessed by an attuned state of reverie on the part of the therapist.

\section{REVERIE, RIGHT BRAIN COMMUNICATION, AND VITAL INTERPRETATIONS}

Reverie as understood by both developmental neurobiology and psychoanalysis is a mind/body state of creatively attuned empathic resonance in which the analyst is both open to the patient's verbal and non-verbal communications, and simultaneously sustains a heightened sense of self awareness that is tuned in to all levels of their own internal experience in response to the patient's communications. It is an essentially right-brain-toright-brain interaction with the analyst's preconscious receiving and processing internal and external stimuli at all levels (Schore, 2003). This state of mind/body is one of openness to the particular metaphoric language of the patient as the therapist explains (bodily, semantically and prosodically) what his/her experience is like at each moment.

This state of reverie opens up the mental space in the analyst for bilateral interplay between the categorical information and linguistic representations stored and processed predominantly in the left hemisphere and the associational and contextual links to non-verbal, unconscious sensory/affective experience processed predominantly in the right hemisphere. This integrative functioning allows for the translation of sensory and affective experiences and memories into symbolic representation, the development of a 
narrative sense of self and others and the emotional foundation for the associative play of the imagination (Stevens, 2003).

The development of the ability of the analyst to "listen" to their cognitive unconscious and imaginatively "play" in the space created by holding themselves in a state of responsive and fluid reverie allows for a kind of understanding that informs a "vital" interpretation as opposed to an interpretation that is rote or not linked to the moment-to-moment intersubjective experience. This kind of interpretation will be linked both to the metaphoric content of language and non-verbal communication from the patient as opposed to the literal or semantic meaning of words or behavior. Upon the foundation attuned resonance are layered many other abilities that taken together begin to describe the components of a vital interpretation.

These abilities would include the following: to read all the levels and kinds of communications from the patient and from within the analyst in the context of the narrative being "told" by the unconscious of the patient - with the analyst as a co-respondent and vehicle for the story's unfolding; to read and understand the particular language and logic of the particular patient's way of organizing and making meaning out of experience; to unpack metaphors in terms of their expression of meaning for the patient and their linking sensory and affective experience with language; to hear themes and leitmotifs as they weave through the patient's language and history; to hear the subtext/accompaniment underneath and surrounding the dominant themes or literal, semantic content of a communication; to tolerate and listen to silences 
as well as words; and to hear meanings of all kinds of communications on multiple levels at the same time and in terms of past and present simultaneously.

The empathic, attuned, resonant analytic stance provides the containment and space for these abilities and facilitates the imaginative, creative mind of the analyst to link the sensory-embodied-affectiveunconscious cognitive experience of being with the patient to her knowledge of the patient's history, the history of the analytic relationship, the realistic details of the adaptive context of the life of the patient at the time of each session, as well as their knowledge of her own history, theoretical biases and assumptions and somatic/affective/behavioral signals of counter-transference reactions. These myriad abilities taken together are part of what is meant by the term "intuition" and guide the analyst's sense of timing as well as the content of an interpretation.

I believe that this is a skill that can and needs to be developed as an essential tool for psychoanalytic and psychotherapeutic work. As Poincare said in 1908:

A first hypothesis presents itself: the subliminal self is in no way inferior to the conscious self; it is not purely automatic; it is capable of discernment; it has tact, delicacy; it knows how to choose, to divine...It knows better how to divine than the conscious self, since it succeeds where that has failed (in Hadamard, 1948, p.23).

The contributions of interpersonal neurobiology, psychoanalytic theory and technique and cognitive science are combining to create a vital 
interchange and exploration of ideas of the development of an embodied mind. This questioning and discussion will lead to important insights as to what kinds of experiences and techniques inform an analyst's ability to facilitate the process of awareness, insight and transformation for patients. Important among these insights are the notion that the cognitive unconscious imagination can be trained, that intuition is a skill that can be honed and developed in both the analyst and patient, and that the concept of interpretation needs to be freed from its semantic, verbal and conscious cognitive moorings.

\section{REFERENCES}

Anaki, D., Faust, M., \& Kravetz, S. (1998). Cerebral hemispheric asymmetries in processing lexical metaphors. Neuropsychologia, 36, 353-362.

Hadamard, J. (1945). The mathematician's mind: The psychology of invention in the mathematical field. Princeton NJ: Princeton University Press.

Lakoff, G, \& Johnson, M. (1999). Philosophy in the flesh: the embodied mind and its challenge to western thought. New York: Basic Books

Ogden, T. (2001). Conversations at the frontier of dreaming. Northvale NJ: Jason Aronson, Inc.

Ricoeur, P. (1974). The conflict of interpretations. Evanston III: Northwestern University Press.

Schore, A. (2001). Effects of a secure attachment relationship on right brain development, affect regulation, and infant mental health. Infant Mental Health Journal, 22, 7-66. 
Schore, A. (2003). Affect regulation and the repair of the self. New York: W.W. Norton \& Co.

Stevens, V. (2003). Reading the language of the right brain: fine-tuning the analyst's capacity for creatively attuned empathic resonance. Psychologist Psychoanalyst, 23, No. 4.

Stevens, W. (1954). The collected poems of Wallace Stevens. New York: Knopf. Wapner, W., Hamby, S., \& Gardner, H. (1981). The role of the right hemisphere in the apprehension of complex linguistic materials. Brain \& Language, $14,15-33$.

Dr. Victoria Stevens is in private practice in West Los Angeles, a graduate of the Psychoanalytic Center of California, and a faculty member of the California Institute of the Arts. vickis@earthlink.net. 